\title{
Impaired pneumococcal antibody response in bronchiectasis of unknown aetiology
}

\author{
D.A. van Kessel*, H. van Velzen-Blad" , J.M.M. van den Bosch* and G.T. Rijkers ${ }^{\natural}$
}

ABSTRACT: As a defective anti-polysaccharide response can exist in the absence of an immunoglobulin deficiency, a series of 26 patients with bronchiectasis of unknown aetiology was vaccinated with a 23-valent pneumococcal polysaccharide vaccine. All patients suffered from recurrent respiratory tract infections.

When measuring total antibody levels to pneumococcal serotypes 3, 4 and 9, a normal polysaccharide antibody response was found in 22 patients. However, only 11 of these subjects showed a normal pneumococcal antibody response within the IgA and/or IgG2 subclass, and thus could be classified as true responders, while 15 patients did not respond in either the IgA class or in the IgG2 subclass.

When analysing differences between the responder $(n=11)$ and nonresponder $(n=15)$ groups, the latter demonstrated higher frequencies of respiratory tract infections and more severe lung pathology, as revealed by the presence of more bronchi visualised in the peripheral third of the lung by high-resolution computed tomography scanning. Moreover, nonresponders needed extensive lung surgery more often in order to control their disease (number of resected segments eight versus five).

In conclusion, an important fraction of patients presenting with idiopathic bronchiectasis is associated with a selective anti-polysaccharide response deficiency and this subgroup appears to represent a more severe clinical phenotype. Therefore, it can be regarded as a separate clinical entity with possible therapeutic targets.

In order to identify IgA and IgG2 anti-polysaccharide nonresponders, all patients presenting with bronchiectasis of unkown aetiology should be immunised with a pneumococcal polysaccharide vaccine, and IgA and IgG2 isotype responses should be evaluated as well as the total antibody response.

KEYWORDS: Antibody response, bronchiectasis, high-resolution computed tomography scan, IgA, IgG2, pneumococcal polysaccharide

50 ronchiectasis is defined as chronic dilatation of bronchi, which is presently best diagnosed by high-resolution computed tomography (HRCT) of the chest [1]. Patients with bronchiectasis can be asymptomatic, but many suffer from recurrent respiratory tract infections, with productive cough, dyspnoea and occasionally haemoptysis. Disease severity can range from mild disease requiring only antibiotics on demand, to severe forms, which may evolve into end-stage lung disease, ultimately requiring lung transplantion [2].

There are many known causes of bronchiectasis, which can be grouped into extrinsic (postinfectious) and intrinsic (noninfectious) causes. In the past, bronchiectasis was most commonly a post-infectious complication [3]. However, since the introduction of antibiotics, effective tuberculostatic drugs and the widespread implementation of childhood vaccination programmes, the incidence of post-infectious bronchiectasis has dramatically decreased. At present, bacterial infections in cystic fibrosis (CF) and allergic bronchopulmonary aspergillosis (ABPA) are amongst the most frequent forms of post-infectious bronchiectasis encountered in pulmonary medicine $[4,5]$.

Intrinsic causes of bronchiectasis include $\alpha_{1}$ antitrypsin deficiency, mucociliary clearance defects, rheumatoid arthritis and various forms of (humoral) immunodeficiency. In particular, patients with an impaired antibody response to encapsulated bacteria are thought to be at risk for recurrent respiratory tract infections, which may lead to bronchiectasis.
AFFILIATIONS

Depts of *Pulmonology and

\#Medical Microbiology \&

Immunology, Sint Antonius Hospital, Nieuwegein, and

'Dept of Immunology, Wilhelmina Children's Hospital, Utrecht, The Netherlands.

CORRESPONDENCE

G.T. Rijkers

Dept of Immunology

University Medical Center Utrecht

Wilhelmina Children's Hospital

P0 Box 85090

3508 AB Utrecht

The Netherlands

Fax: 31302505311

E-mail: grijkers@wkz.azu.nl

Received:

June 172004

Accepted after revision

October 122004 
A selective anti-polysaccharide antibody deficiency can be present in individuals with normal total immunoglobulin levels. Ambrosino et al. [6] were the first to describe this phenomenon, which was later confirmed by others [7] Therefore, currently, a selective anti-polysaccharide antibody deficiency is a well-recognised entity in the context of recurrent respiratory tract infections.

Anti-pneumococcal antibody responses predominantly reside in the $\operatorname{IgA}$ and IgG2 subclasses. It has previously been demonstrated by the current authors that defective $\operatorname{IgA}$ antibody responses can be found after vaccination with a 23valent pneumococcal polysaccharide vaccine in patients with recurrent sinusitis, despite normal total serum immunoglobulin levels [8]. In addition, in the same paper, defective IgG2 antibody responses were reported upon pneumococcal polysaccharide vaccination in patients presenting with pneumonia [8]. Therefore, these results prompted an extension of the study to include antibody responses to pneumococcal polysaccharide vaccination in patients with idiopathic bronchiectasis and normal total serum immunoglobulin levels.

\section{PATIENTS AND METHODS Patient population}

The study was designed as a consecutive clinical attendees' cohort study, which included 26 patients who were recruited at the outpatient pulmonary department of the Sint Antonius Hospital (Nieuwegein, The Netherlands). All patients complained of recurrent respiratory tract infections caused by bronchiectasis. Twenty-three patients were female, which is a common finding in idiopathic bronchiectasis [9]. Subjects were included when serum levels of immunoglobulins, IgG1 and G2 subclasses, and $\operatorname{IgE}$ were within the normal range: $\operatorname{Ig} \mathrm{A} 0.5-$ $3.7 \mathrm{~g} \cdot \mathrm{L}^{-1}, \mathrm{IgM} 0.4-2.3 \mathrm{~g} \cdot \mathrm{L}^{-1}, \mathrm{IgG} 8-17 \mathrm{~g} \cdot \mathrm{L}^{-1}, \mathrm{IgG} 14.9-11.4 \mathrm{~g} \cdot \mathrm{L}^{-1}$, IgG2 $1.5-6.4 \mathrm{~g} \cdot \mathrm{L}^{-1}, \mathrm{IgE}<100 \mathrm{kU} \cdot \mathrm{L}^{-1}$.

Bronchiectasis patients with a history of tuberculosis or exposure to Mycobacterium tuberculosis (based on a positive tuberculin skin test), those with indications for aspiration or with severe respiratory infections during childhood were excluded. CF was excluded by a sweat test and/or genotyping the CF transmembrane regulator gene (two patients).

As hypersensitivity reactions to Aspergillus fumigatus can play a role in the development of bronchiectasis [10], precipitating antibodies to $A$. fumigatus were determined. All but two patients scored negative in this test. The two patients with precipitins to A. fumigatus did not meet the other clinical and laboratory parameters for the diagnosis of ABPA (asthma, elevated total serum IgE, positive immediate skin test to $A$. fumigatus, serum IgE antibodies, blood eosinophilia, increased serum IgE and central bronchiectasis [11]). $\alpha_{1}$-Antitrypsin deficiency was excluded by normal serum levels of $\alpha_{1}$ antitrypsin. Primary ciliary dyskinesia was excluded by histological examination of nasal or bronchial biopsies in 10 patients or by analysis of mucociliary transport using ${ }^{99 \mathrm{~m}} \mathrm{Tc}-$ labelled albumen in the remainder.

The respiratory tract infection frequency of each patient was carefully assessed and based on reported infectious episodes. Infectious episodes were categorised as sinusitis, bronchitis or pneumonia. Sinusitis was defined as symptomatic inflammation of the paranasal sinuses lasting no longer than 6-8 weeks. Bronchitis was defined as having excessive mucous secretion [12]. A sputum culture was performed if possible. Chest radiography was always used to confirm the clinical diagnosis of pneumonia.

Pulmonary function testing was carried out according to the standards of the European Respiratory Society [13, 14].

\section{Laboratory investigations}

Standard laboratory investigations in all subjects included a blood leukocyte count with differentiation, serum $\alpha_{1^{-}}$ antitrypsin measurement, and determination of serum levels of immunoglobulins and IgG subclasses, which was performed by nephelometry or radial immunodiffusion [15]. Sputum was cultured using standard microbiological techniques.

All patients in the study were immunised intramuscularly with a 23-valent pneumococcal vaccine (Pneumovax; Merck and Co., Rahway, NJ, USA), containing $25 \mu \mathrm{g}$ of purified typespecific capsular polysaccharides of 23 pneumococcal serotypes $(1,2,3,4,5,6 \mathrm{~B}, 7 \mathrm{~F}, 8,9 \mathrm{~N}, 9 \mathrm{~V}, 10 \mathrm{~A}, 11 \mathrm{~A}, 12 \mathrm{~F}, 14,15 \mathrm{~B}, 17 \mathrm{~F}$, 18C, 19F, 19A, 20, 22F, 23F and 33F; Danish nomenclature). Blood samples were drawn before and 3 weeks after immunisation. Serum samples were stored at $-20^{\circ} \mathrm{C}$ until use.

\section{Anti-capsular polysaccharide antibody assays}

Antibodies to capsular polysaccharides of Streptococcus pneumonia serotypes 3, 4 and $9 \mathrm{~V}$ in pre- and post-immunisation serum samples were measured by ELISA [16]. In addition, isotype-specific antibodies (IgA, IgG1 and IgG2) to serotypes 4, $6 \mathrm{~B}, 9 \mathrm{~V}, 14,19 \mathrm{~F}$ and $23 \mathrm{~F}$ were measured in pre- and postimmunisation samples. All antibody titres were calibrated on the international reference preperation 89-SF [16-18]. Antibody concentrations in the reference preparation were assigned $100 \mathrm{U} \cdot \mathrm{mL}^{-1}$ for each isotype and each serotype (figs 1 and 2).

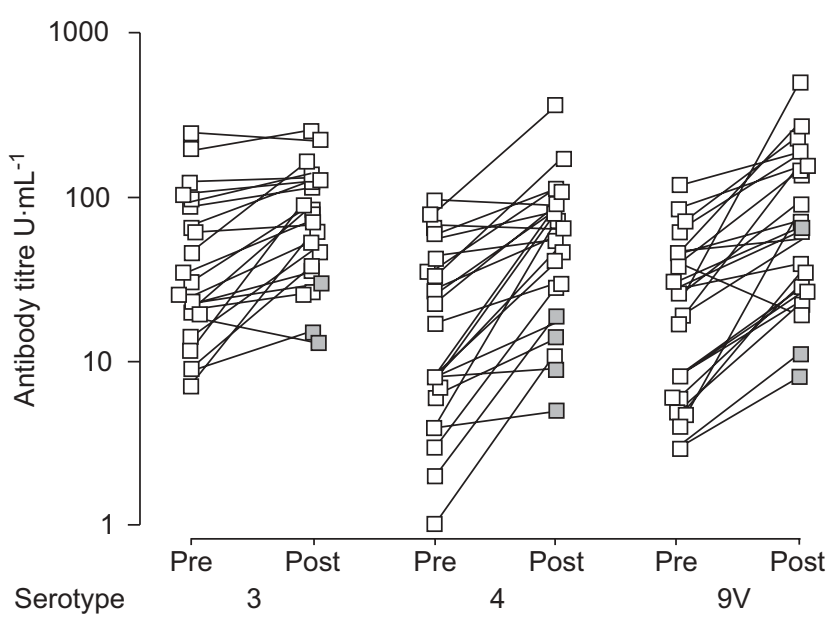

FIGURE 1. Antibody response to pneumococcal serotypes 3,4 and $9 \mathrm{~V}$ Antibody titres were measured before (pre) and 21 days after (post) vaccination with 23-valent pneumococcal polysaccharide vaccine. An antibody concentration of $100 \mathrm{U} \cdot \mathrm{mL}^{-1}$ corresponds with $7.29 \mu \mathrm{g} \cdot \mathrm{mL}^{-1}$ anti-serotype $3,6.63 \mu \mathrm{g} \cdot \mathrm{mL}^{-1}$ antiserotype 4 and $10.26 \mu \mathrm{g} \cdot \mathrm{mL}^{-1}$ anti-serotype $9 \mathrm{~V}$. $\square$ : nonresponders; $\square$ : responders. 

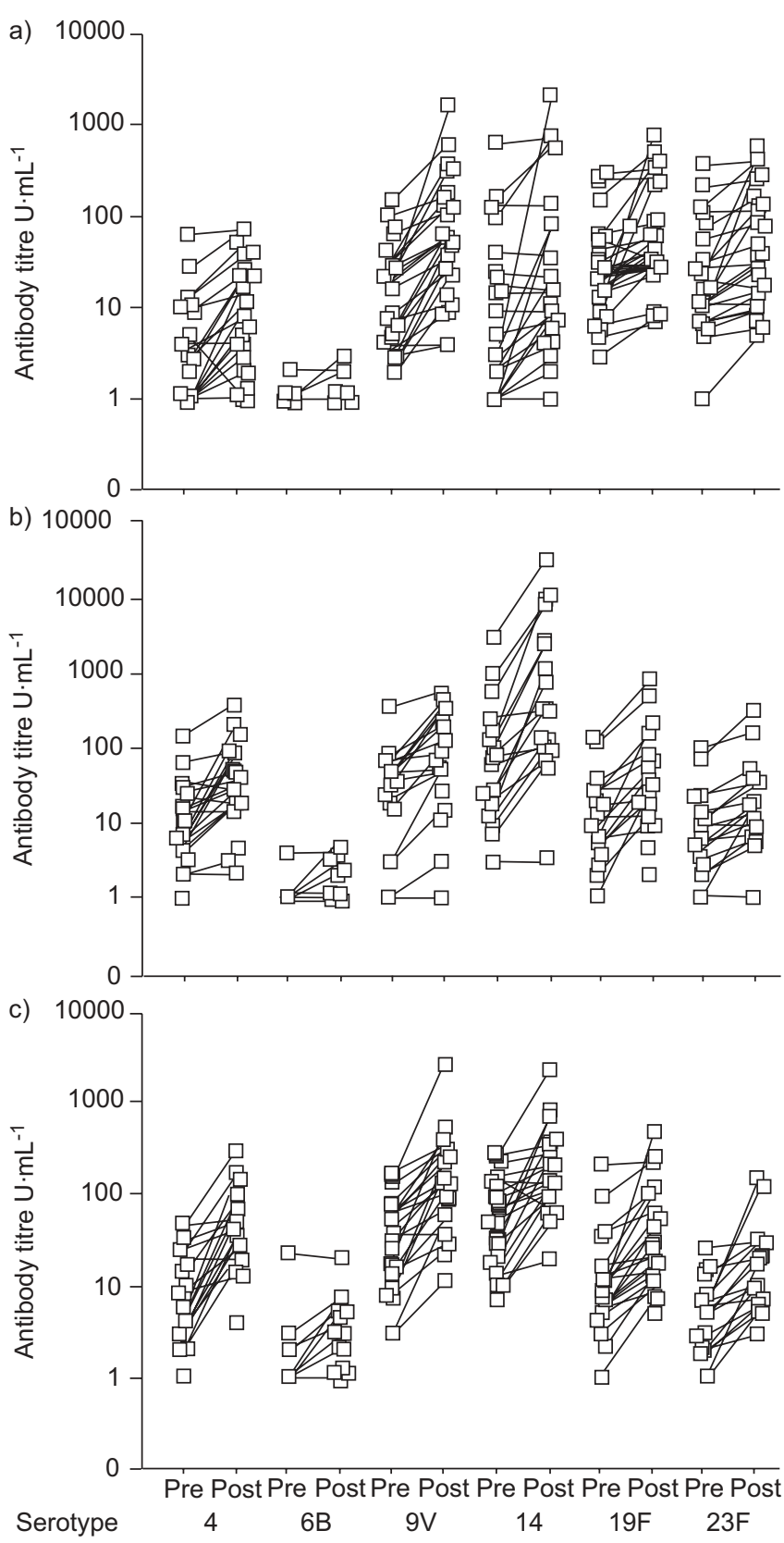

FIGURE 2. a) $\lg G 1$, b) $\lg G 2$ and c) $\lg A$ antibody responses to pneumococcal serotypes 4, 6B, 9V, 14, 19F and 23F. Antibody titres were measured before (pre) and 21 days after (post) vaccination with 23-valent pneumococcal polysaccharide vaccine. An antibody concentration of $100 \mathrm{U} \cdot \mathrm{mL}^{-1}$ corresponds with $0.48 \mu \mathrm{g} \cdot \mathrm{mL}^{-1}$ IgG1, $3.59 \mu \mathrm{g} \cdot \mathrm{mL}^{-1} \mathrm{lgG} 2,1.18 \mu \mathrm{g} \cdot \mathrm{mL}^{-1} \mathrm{lgA}$ anti-serotype $4 ; 0.66 \mu \mathrm{g} \cdot \mathrm{mL}^{-1} \mathrm{lgG} 1$, $10.54 \mu \mathrm{g} \cdot \mathrm{mL}^{-1} \mathrm{IgG} 2,1.52 \mu \mathrm{g} \cdot \mathrm{mL}^{-1} \mathrm{IgA}$ anti-serotype $6 \mathrm{~B} ; 0.80 \mu \mathrm{g} \cdot \mathrm{mL}^{-1} \mathrm{IgG} 1$, $6.10 \mu \mathrm{g} \cdot \mathrm{mL}^{-1} \mathrm{IgG} 2,1.70 \mu \mathrm{g} \cdot \mathrm{mL}^{-1} \mathrm{IgA}$ anti-serotype $9 \mathrm{~V} ; 2.87 \mu \mathrm{g} \cdot \mathrm{mL}^{-1} \mathrm{IgG} 1$, $21.23 \mu \mathrm{g} \cdot \mathrm{mL}^{-1} \quad \mathrm{ggG} 2,1.94 \mu \mathrm{g} \cdot \mathrm{mL}^{-1} \mathrm{IgA}$ anti-serotype $14 ; 1.12 \mu \mathrm{g} \cdot \mathrm{mL}^{-1} \quad \mathrm{ggG} 1$, $10.09 \mu \mathrm{g} \cdot \mathrm{mL}^{-1} \mathrm{lgG} 2,1.98 \mu \mathrm{g} \cdot \mathrm{mL}^{-1} \mathrm{lgA}$ anti-serotype $19 \mathrm{~F} ; 0.73 \mu \mathrm{g} \cdot \mathrm{mL}^{-1} \mathrm{IgG} 1$, $6.66 \mu \mathrm{g} \cdot \mathrm{mL}^{-1} \operatorname{lgG} 2,1.29 \mu \mathrm{g} \cdot \mathrm{mL}^{-1} \mathrm{IgA}$ anti-serotype $23 \mathrm{~F}$.

Patients were classified as total responders or nonresponders on the basis of their total pneumococcal polysaccharide antibody response after vaccination. A responder was defined as having a post-vaccination titre $>20 \mathrm{U} \cdot \mathrm{mL}^{-1}$ and at least a two-fold increase for two of the three pneumococcal serotypes tested.

To allow for statistical analysis, the IgA and IgG2 antibody levels to pneumococcal serotypes $4,6 \mathrm{~B}, 9 \mathrm{~V}, 14,19 \mathrm{~F}$ and $23 \mathrm{~F}$ in post-immunisation samples were converted into positive $\left(>50 \mathrm{U} \cdot \mathrm{mL}^{-1}\right)$ or negative $\left(<50 \mathrm{U} \cdot \mathrm{mL}^{-1}\right)$. An isotype responder was defined as having a positive IgA and/or IgG2 antibody response to more than four out of six of the serotypes tested.

\section{Radiological classification}

The presence, severity and extent of bronchiectasis were determined by bronchography [19] in two patients and by HRCT in 24 patients. HRCT scanning was carried out with a Philips SR 7000 CT-scanner (Philips, Eindhoven, The Netherlands). Patients were put into the supine position. No (intravenous) contrast material was used. Measurements were made at end-inspiratory volume. Slices $1.5 \mathrm{~mm}$ thick were obtained at $10-\mathrm{mm}$ intervals from the costophrenic angles to the lung apices and reconstructed with a high-spatial algorithm. Scanning parameters included a voltage of $140 \mathrm{kV}$ of $175 \mathrm{~mA}$ with a scan time of $1 \mathrm{~s}$. For images, a window width of $1500 \mathrm{HU}$, a window level of $-750 \mathrm{HU} / 1500 \mathrm{HU}$ and volumetric scanning were used.

The HRCT scans were analysed according to the criteria described by MCGUINNESS et al. [1], NAIDICH et al. [20] and REIFF et al. [21]. This classification system includes three categories: cylindrical, cystic and varicose bronchiectasis. Additionally, another analysis was performed, according to the criteria described by DieDERICH et al. [22]. The major items scored in this system were as follows. 1) Bronchial dilatation as compared with the diameter of the adjacent pulmonary artery was divided into three categories: normal $<110 \%$, mild 110 $150 \%$ and severe $>150 \%$. 2) The luminal diameter of the bronchus as compared with the total diameter of the bronchus was also divided into three categories: normal $>80 \%$, mild 80 $50 \%$ and severe $<50 \%$. 4) The bronchial contents was divided into two categories: air or mucus. 5) The cysts in cystic bronchiectasis were placed into three groups: $<1 \mathrm{~cm}, 1-2 \mathrm{~cm}$ or $>2 \mathrm{~cm}$ in size.

Other signs of severity of disease were recorded as either present or absent: visualisation of bronchi in the peripheral third of the lung, volume loss, pulmonary consolidation, emphysema, interstitial lines and nodules. The extent of abnormal bronchi per lobe was recorded in four categories: $<25 \%$ involvement, $26-50 \%$ involvement, $51-75 \%$ involvement and $>75 \%$ involvement.

\section{Statistics}

The IgG2 and IgA antibody titres to six pneumococcal serotypes in the various patient subgroups were converted into positive or negative and subsequently compared with the Fishers exact test. A p-value $<0.05$ was considered statistically significant.

\section{RESULTS}

A series of 26 patients was included in the study. In 24 subjects the diagnosis bronchiectasis was established based on HRCT of the chest and in two patients based on bronchography. 
After pneumococcal polysaccharide vaccination, 22 patients showed a post-vaccination total antibody titre $>20 \mathrm{U} \cdot \mathrm{mL}^{-1}$ and at least a two-fold increase of two of the three pneumococcal serotypes tested (fig. 1). Therefore, on the basis of this test, 22 patients would have to be classified as responders and four as nonresponders.

However, determination of $\operatorname{IgA}$ and $\operatorname{IgG} 2$ antibodies to pneumococcal polysaccharides of serotypes $4,6 \mathrm{~B}, 9 \mathrm{~V}, 14,19 \mathrm{~F}$ and $23 \mathrm{~F}$ largely changed this classification (fig. 2). Defining an individual with a positive $\operatorname{IgA}$ and/or IgG2 antibody response for more than four out of six serotypes classified them as an isotype responder, an adequate response to the vaccine was observed in only 11 out of 22 responders in the total antibody evaluation. Three of these patients had both an IgA and IgG2 response. The remaining 11 patients had an inadequate $\operatorname{Ig} \mathrm{A}$ and IgG2 response, despite initially being classified as a total responder (table 1 ).

Thus, based on measurement of the post-vaccination total antibody titre and the selective antibody response against pneumococcal polysaccharide in the IgA and IgG2 subclasses, the nonresponder group consisted of four total nonresponders and 11 isotype nonresponders. The clinical characteristics of the nonresponder group $(n=15)$ and that of the responder group $(n=11)$ are summarised in table 2 .

\section{Comparison of clinical characteristics between responders and nonresponders}

In both groups there was a remarkable predominance of females, i.e. 11 in the responder and 12 in the nonresponder group $(\mathrm{p}<0.01)$. Median age was $49 \mathrm{yrs}$ in the responder versus

\begin{tabular}{|c|c|c|c|c|}
\hline \multirow[t]{2}{*}{ TABLE 1} & \multirow[b]{2}{*}{ Responder } & \multirow[b]{2}{*}{ Nonresponder } & \multirow[b]{2}{*}{ Total } & \multirow[b]{2}{*}{$p$-value } \\
\hline & & & & \\
\hline Patients & 11 & 15 & 26 & \\
\hline IgA anti-PPS response & 4 & 0 & 4 & 0.0221 \\
\hline IgG2 anti-PPS response & 10 & 0 & 10 & $<0.001$ \\
\hline \multicolumn{5}{|l|}{ IgA anti-serotype } \\
\hline 4 & 6 & 2 & 8 & 0.0384 \\
\hline $6 \mathrm{~B}$ & 0 & 0 & 0 & \\
\hline $9 \mathrm{~V}$ & 9 & 13 & 22 & \\
\hline 14 & 10 & 14 & 24 & \\
\hline $19 F$ & 6 & 3 & 9 & \\
\hline $23 \mathrm{~F}$ & 2 & 0 & 2 & \\
\hline \multicolumn{5}{|l|}{ IgG2 anti-serotype } \\
\hline 4 & 9 & 2 & 11 & $<0.001$ \\
\hline $6 \mathrm{~B}$ & 0 & 0 & 0 & \\
\hline $9 \mathrm{~V}$ & 10 & 6 & 16 & 0.0143 \\
\hline 14 & 11 & 13 & 24 & \\
\hline $19 F$ & 11 & 5 & 16 & $<0.001$ \\
\hline $23 \mathrm{~F}$ & 7 & 0 & 7 & $<0.001$ \\
\hline
\end{tabular}

Data are presented as $n$ patients. PPS: pneumococcal polysaccharides. IgA and/or IgG2 isotype responder is defined as a post-vaccination titre $>50 \mathrm{U} \cdot \mathrm{mL}^{-1}$ for more than four out of six pneumococcal serotypes tested.
TABLE 2 Clinical characteristics of the nonresponder and responder groups

\begin{tabular}{lcccc} 
& Responder & Nonresponder & Total & p-value \\
\hline Patients & 11 & 15 & 26 & \\
Female/male & $11 / 0$ & $12 / 3$ & $23 / 3$ & \\
Median age yrs & $50(20-69)$ & $49(25-69)$ & $49(20-69)$ & \\
FEV 1 \% pred & & & & \\
$\quad$ Normal $\geqslant 80 \%$ & 5 & 9 & 14 & \\
$\quad$ Mild 70-79 & 1 & 2 & 3 & \\
$\quad$ Moderate 50-69 & 4 & 2 & 6 & \\
$\quad$ Severe $<50$ & 1 & 2 & 3 & \\
Pneumonia & 10 & 12 & 22 & \\
Sinusitis & 8 & 13 & 21 & \\
Allergy & 4 & 7 & 11 & \\
Smoking & 1 & 1 & 2 & \\
Corticosteroids & 1 & 0 & 1 & \\
Antibiotics & 1 & 4 & 5 & \\
IgG4 deficiency & 1 & 1 & 2 & \\
Infections per yr & $5(3-12)$ & $8(4-12)$ & $8(3-12)$ & 0.078 \\
S. pneumonia & 4 & 8 & 12 & \\
H. influenzae & 7 & 12 & 19 & \\
M. catarrhalis & 2 & 7 & 9 & 0.06 \\
Surgery & 4 & 8 & 12 & \\
Resected segments & & 8 & & \\
$\quad$ mean & 3 & & & \\
\hline & & & & \\
\hline
\end{tabular}

Data are presented as $\mathrm{n}$ patients or median (range). FEV1: forced expiratory volume in one second. Fishers exact test was used to compare the two groups.

$50 \mathrm{yrs}$ in the nonresponder group. No difference was observed in distribution of smoking behaviour, allergic constitution and use of antibiotics or corticosteroids.

Analysis of lung function showed normal values of forced expiratory volume in one second in five individuals $(45 \%)$ of the responder group and in nine $(60 \%)$ of the nonresponder group. In total, nine patients had a mild-to-moderate impairment and only three patients showed severe obstructive lung disease. Statistical analysis of these results showed no significant differences.

The number of respiratory tract infections ranged from three to 12 per year. The nonresponder group showed a higher number of infections, as illustrated in figure 3.

Four patients underwent surgery in the responder group versus eight patients in the nonresponder group. Importantly, the nonresponders required more extensive surgery than the responders.These data indicate that patients with a defective pneumococcal antibody response show a higher infection frequency and require more extensive surgery.

\section{Radiological evaluation of reponders and nonresponders}

Results of evaluation of radiological characteristics in responder and nonresponder bronchiectasis patients are summarised in table 3. Cylindrical bronchiectasis was the predominant finding in both groups. Three patients with cystic bronchiectasis were present in each group. No differences were found in scoring for bronchial contents and bronchial thickening, 


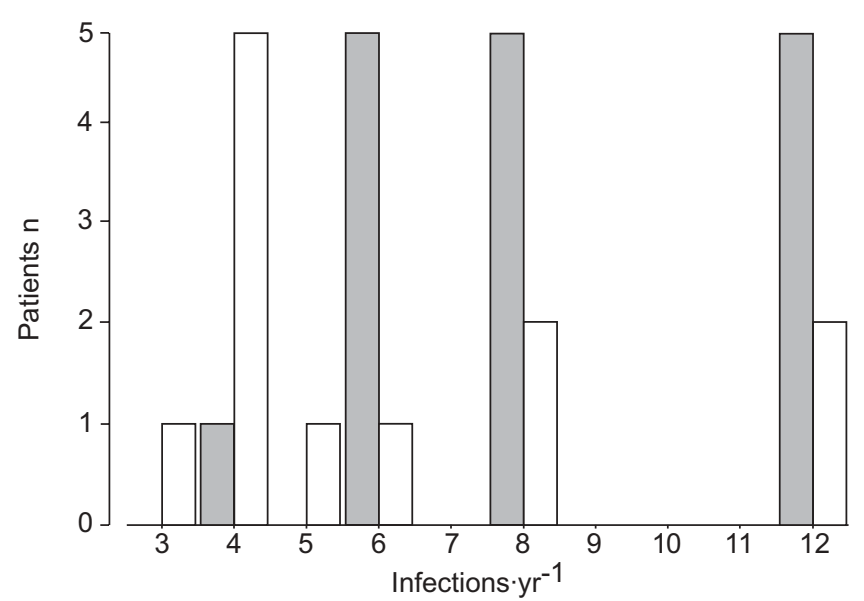

FIGURE 3. Infection frequency in pneumococcal polysaccharide IgA or IgG2 antibody responders $(\square)$ and nonresponders ( $\square$ ).

volume loss and consolidation. Signs of emphysema were equally seen in both groups. There were significantly more visible bronchi in the peripheral third of the lung in the nonresponder group $(p=0.0472)$, indicating more severe bronchiectasis [23].

The extent of areas with abnormal bronchi per lobe was determined in all available HRCT scans. In agreement with previous data in the literature, the lower lobes tended to be more severly affected, and this was most prevalent in the nonresponding group (fig. 4) [2].

In 11 patients a follow-up HRCT scan was performed because of the high infection frequency. Ten of them were nonresponders. In four patients the HRCT scan showed progression of bronchiectasis.

\section{DISCUSSION}

It is shown in the present study that $~ 50 \%$ of the patients with idiopathic bronchiectasis and normal total serum immunoglobulin levels had a defective IgA and IgG2 anti-polysaccharide response. Clinically, these nonresponders demonstrated a higher rate of respiratory tract infections and showed more severe lung pathology as assessed by HRCT scanning. Humoral immunodeficiencies, including common variable hypogammaglobulinaemia and IgA or IgG2 subclass deficiency, are well-recognised aetiological risk factors for bronchiectasis [2].

As antibodies to pneumococcal polysaccharides predominantly reside in the IgA and IgG2 subclasses, it could be anticipated that bronchiectasis patients with defective antipolysaccharide antibody responses show insufficient levels of anti-polysaccharide IgA and IgG2 upon vaccination with pneumococcal-derived polysaccharide. Selective antipolysaccharide antibody deficiency is associated with a variable clinical spectrum of recurrent and/or severe respiratory tract infections $[7,24]$. Bronchiectasis develops because respiratory pathogens are not handled adequately due to this humoral immunodeficiency, which results in permanent damage of lung tissue.

\section{TABLE 3 Radiological characteristics}

\begin{tabular}{|c|c|c|c|}
\hline & Responder & Nonresponder & Total \\
\hline Patients & 11 & 13 & 24 \\
\hline \multicolumn{4}{|l|}{ Bronchiectasis } \\
\hline Mild dilatation & 11 & 13 & 24 \\
\hline Severe dilatation & 0 & 0 & 0 \\
\hline \multicolumn{4}{|l|}{ Type of bronchiectasis } \\
\hline Cylindrical & 6 & 6 & 12 \\
\hline Cystic & 1 & 2 & 3 \\
\hline Varicose & 0 & 1 & 1 \\
\hline Indeterminate & 0 & 0 & 0 \\
\hline More than one type & 4 & 4 & 8 \\
\hline \multicolumn{4}{|l|}{ Cystic bronchiectasis } \\
\hline None & 10 & 12 & 22 \\
\hline $1-2 \mathrm{~cm}$ average size & 1 & 1 & 2 \\
\hline \multicolumn{4}{|l|}{ Bronchial wall thickening } \\
\hline Mild thickening $>50 \%$ normal & 10 & 13 & 23 \\
\hline Severe thickening $<50 \%$ normal & 1 & 0 & 1 \\
\hline \multicolumn{4}{|l|}{$\begin{array}{l}\text { Bronchial dilatation and wall } \\
\text { thickening }\end{array}$} \\
\hline None & 1 & 1 & 2 \\
\hline Yes & 10 & 12 & 22 \\
\hline \multicolumn{4}{|l|}{ Bronchial contents } \\
\hline Air only & 8 & 10 & 18 \\
\hline Air and fluid & 3 & 3 & 6 \\
\hline \multicolumn{4}{|l|}{$\begin{array}{l}\text { Bronchi visualised in the } \\
\text { peripheral third of the lung }\end{array}$} \\
\hline No & 9 & 5 & 14 \\
\hline Yes & 2 & 8 & $10^{\#}$ \\
\hline \multicolumn{4}{|l|}{ Volume loss } \\
\hline No & 10 & 9 & 19 \\
\hline Yes & 1 & 4 & 5 \\
\hline \multicolumn{4}{|l|}{ Consolidation } \\
\hline No & 5 & 8 & 13 \\
\hline Yes & 6 & 5 & 11 \\
\hline \multicolumn{4}{|l|}{ Emphysema } \\
\hline No & 10 & 10 & 20 \\
\hline Yes & 1 & 3 & 4 \\
\hline \multicolumn{4}{|l|}{ Interstitial lines } \\
\hline No & 9 & 6 & 15 \\
\hline Yes & 2 & 7 & 9 \\
\hline
\end{tabular}

Data are presented as $\mathrm{n}$ patients. ${ }^{\#}: \mathrm{p}=0.0472$. According to the criteria as described by DIEDERICH et al. [22].

It is well recognised that patients with dysimmunoglobulinaemia have a defective anti-polysaccharide antibody response [8]. In addition, in patients with bronchiectasis, in the context of dysimmunoglobulinaemia deficient, anti-polysaccharide antibody responses have been found upon vaccination [4]. However, this study now clearly shows that an antibody response deficiency may exist even in bronchiectasis patients with normal total immunoglobulin levels. Therefore, measurement of $\operatorname{IgA}$ and $\operatorname{IgG}$ subclass levels cannot be used as a substitute for a specific antibody response estimation [25] Consequently, it is advocated that (pneumococcal) vaccination is used to reveal specific antibody response deficiencies in apparently normal total immunoglobulin subclasses. 

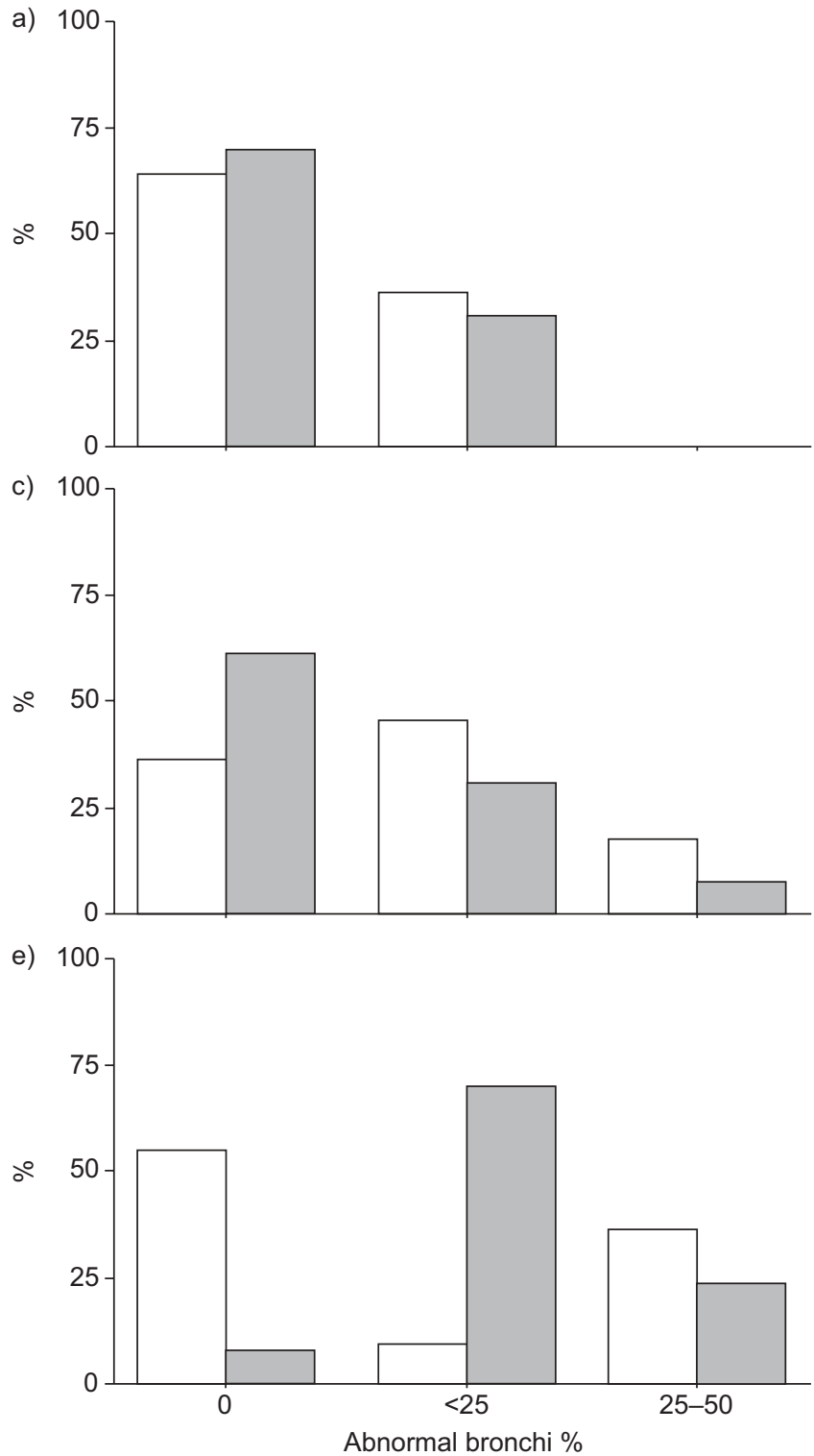

b)

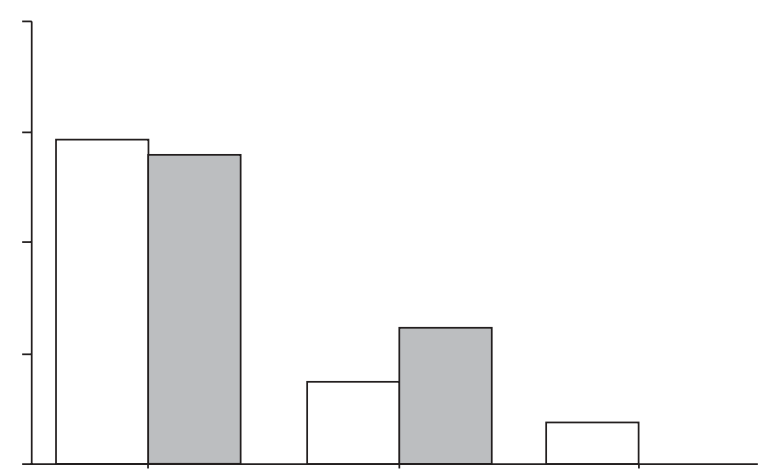

d)

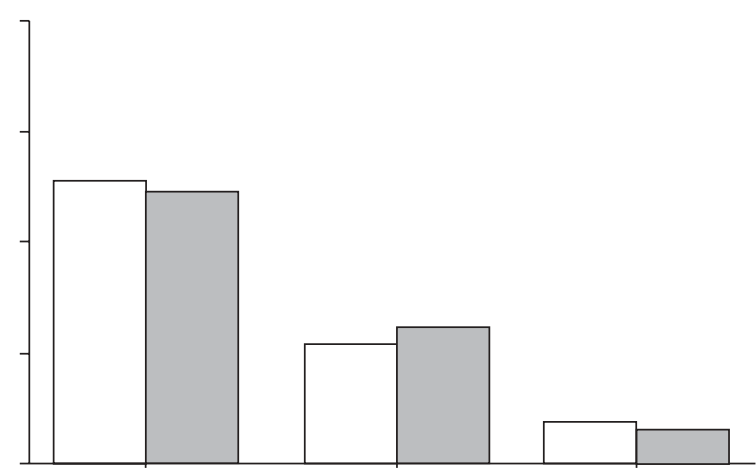

f)

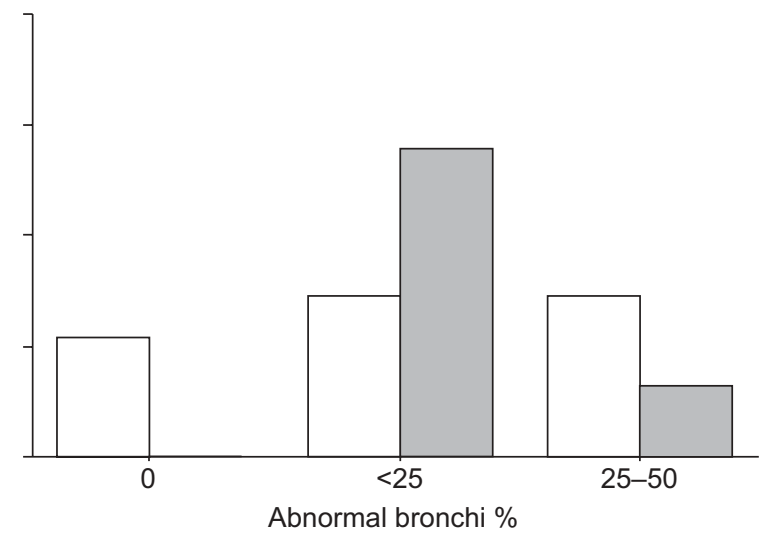

FIGURE 4. High-resolution computed tomography (HRCT) analysis of bronchial abnormalities. The extent of radiological abnormalities is calculated as percentage category of abnormal bronchi in right (R) or left (L), upper (U), middle (M) or lower (L) lobes and in the lingual (LIN): a) RUL, b) LUL, c) RML, d) LIN, e) RLL, f) LLL. $\square$ : responders; : $:$ : nonresponders.

Pneumococcal vaccination in patients with bronchiectasis of unknown cause has been carried out in several studies and the response to vaccination has been measured by determination of total antibody concentrations to a mixture of 23 polysaccharides $[4,26,27]$. In all these studies the vast majority of patients showed a normal response and, therefore, it was recommended that such screening is not required [22]. Our initial screening procedure for anti-polysaccharide antibody deficiency also comprised determination of total antibody levels to pneumococcal serotypes 3, 4 and 9, which represent strong, intermediate and poor immunogenic polysaccharides, respectively. When using this approach a normal polysaccharide antibody response was found in 22 out of 26 patients studied. Hence, using the above screening only, 11 out of 15 of the nonresponder patients would have been missed. The extended screening procedure for specific $\operatorname{IgA}$ and IgG2 antibody levels identified a significant number of nonresponders who initially had a normal total polysaccharide antibody response. Apparently, low levels of IgA and IgG2 antibodies are quantitatively compensated by other isotypes, notably $\operatorname{IgM}$. Identification of the antibody deficiency required testing the response to six pneumococcal serotypes (in the $\operatorname{IgG} 2$ and $\operatorname{IgA}$ class). The failure to respond was not associated with any particular serotype lack of response (table 1). Notably, there were no antibody responders to serotype 6B in either group; almost all patients had an $\operatorname{IgG} 2$ and $\operatorname{IgA}$ response to serotype 14 .

From the clinical management point of view, it is important to recognise that nonresponder patients have a higher infection frequency, show more radiological abnormalities and have 
more extensive lung pathology. Of note, the radiological evaluation of bronchiectasis used in this study was based on the methodology as described by NAIDICH et al. [20], combined with criteria formulated by DIEDERICH et al. [22]. This approach enabled the scoring of severity and extension of lung pathology. In the current series, cylindrical, mild bronchiectasis was mainly found, and only one patient showed progression of bronchiectasis on follow-up HRCT scan. No relationship was found between the clinical symptoms and disease progression on HRCT scan. This is in agreement with the fact that there is, to date, no satisfactory radiological scoring system for severity and progression of bronchiectasis [28].

In the authors opinion, a sizeable fraction of patients with bronchiectasis of unknown cause can now be classified as bronchiectasis associated with polysaccharide antibody response deficiency, which might have important clinical implications for treatment. In patients with hypogammaglobulinaemia, immunoglobulin replacement therapy reduces the infection episodes and prevents further damage of the bronchi $[29,30]$. In this present patient group with a defective IgG2 antibody response, immunoglobulin replacement might supplement the polysaccharide antibodies, but this would require screening of batches with sufficient polysacharide antibody titres, as well as monitoring antibody levels in patients on substitution therapy.

In conclusion, all patients with bronchiectasis of unknown aetiology should be immunised with a pneumococcal polysaccharide vaccine. In addition, specific antibody responses within the IgA and IgG2 subclass should be evaluated as well as the total antibody response to identify this potentially new brochiectasis phenotype.

\section{ACKNOWLEDGEMENTS}

The authors would like to thank J.C. Grutters for valuable advice during performance of the study and preparation of the manuscript. The technical assistance of M. van Schaik and secretarial assistance of J. van der Sluis is gratefully acknowledged.

\section{REFERENCES}

1 McGuinness G, Naidich DP, Leitman BS, McCauley DI. Bronchiectasis: CT evaluation. AJR Am J Roentgenol 1993; 160: 253-259.

2 Barker AF. Bronchiectasis. N Engl J Med 2002; 346: 1383-1393.

3 Barker AF, Bardana EJ Jr. Bronchiectasis: update of an orphan disease. Am Rev Respir Dis 1988; 137: 969-978.

4 Pasteur MC, Helliwell SM, Houghton SJ, et al. An investigation into causative factors in patients with bronchiectasis. Am J Respir Crit Care Med 2000; 162: 1277-1284.

5 Shah PL, Mawdsley S, Nash K, Cullinan P, Cole PJ, Wilson R. Determinants of chronic infection with Staphylococcus aureus in patients with bronchiectasis. Eur Respir J 1999; 14: 1340-1344.

6 Ambrosino DM, Siber GR, Chilmonczyk BA, Jernberg JB, Finberg RW. An immunodeficiency characterized by impaired antibody responses to polysaccharides. $N$ Engl J Med 1987; 316: 790-793.
7 Rijkers GT, Sanders LA, Zegers BJ. Anti-capsular polysaccharide antibody deficiency states. Immunodeficiency 1993; 5: 1-21.

8 Van Kessel DA, Horikx PE, Van Houte AJ, De Graaff CS, Velzen-Blad H, Rijkers GT. Clinical and immunological evaluation of patients with mild IgG1 deficiency. Clin Exp Immunol 1999; 118: 102-107.

9 Keistinen T, Saynajakangas O, Tuuponen T, Kivela SL. Bronchiectasis: an orphan disease with a poorly-understood prognosis. Eur Respir J 1997; 10: 2784-2787.

10 Barker AF, Craig S, Bardana EJ Jr. Humoral immunity in bronchiectasis. Ann Allergy 1987; 59: 179-182.

11 Patterson R, Greenberger PA, Harris KE. Allergic bronchopulmonary aspergillosis. Chest 2000; 118: 7-8.

12 Fletcher CM, Pride NB. Definitions of emphysema, chronic bronchitis, asthma, and airflow obstruction: 25 years on from the Ciba symposium. Thorax 1984; 39: 81-85.

13 Siafakas NM, Vermeire P, Pride NB, et al. Optimal assessment and management of chronic obstructive pulmonary disease (COPD). The European Respiratory Society Task Force. Eur Respir J 1995; 8: 1398-1420.

14 Quanjer PH, Tammeling GJ, Cotes JE, et al. Symbols, abbreviations and units. Working Party Standardization of Lung Function Tests, European Community for Steel and Coal. Eur Respir J 1993; 6: Suppl. 16, 85-100.

15 Vlug A, Nieuwenhuys EJ, van Eijk RV, Geertzen HG, Van Houte AJ. Nephelometric measurements of human IgG subclasses and their reference ranges. Ann Biol Clin (Paris) 1994; 52: 561-567.

16 Sanders EA, Rijkers GT, Kuis W, et al. Defective antipneumococcal polysaccharide antibody response in children with recurrent respiratory tract infections. J Allergy Clin Immunol 1993; 91: 110-119.

17 Quataert SA, Kirch CS, Wiedl LJ, et al. Assignment of weight-based antibody units to a human antipneumococcal standard reference serum, lot 89-S. Clin Diagn Lab Immunol 1995; 2: 590-597.

18 Soininen A, Seppala I, Wuorimaa T, Kayhty H. Assignment of immunoglobulin G1 and G2 concentrations to pneumococcal capsular polysaccharides 3,6B, 14, 19F, and 23F in pneumococcal reference serum 89-SF. Clin Diagn Lab Immunol 1998; 5: 561-566.

19 Silverman PM, Godwin JD. CT/bronchographic correlations in bronchiectasis. J Comput Assist Tomogr 1987; 11: 52-56.

20 Naidich DP, McCauley DI, Khouri NF, Stitik FP, Siegelman SS. Computed tomography of bronchiectasis. J Comput Assist Tomogr 1982; 6: 437-444.

21 Reiff DB, Wells AU, Carr DH, Cole PJ, Hansell DM. CT findings in bronchiectasis: limited value in distinguishing between idiopathic and specific types. AJR Am J Roentgenol 1995; 165: 261-267.

22 Diederich S, Jurriaans E, Flower CD. Interobserver variation in the diagnosis of bronchiectasis on high-resolution computed tomography. Eur Radiol 1996; 6: 801-806.

23 Diederich S, Roos N, Thomas M, Peters PE. [Diagnostic imaging in bronchiectases. Value of CT and HRCT]. Radiologe 1996; 36: 550-559.

24 Ambrosino DM, Umetsu DT, Siber GR, et al. Selective defect in the antibody response to Haemophilus influenzae type $b$ in children with recurrent infections and normal 
serum IgG subclass levels. J Allergy Clin Immunol 1988; 81: 1175-1179.

25 Maguire GA, Kumararatne DS, Joyce HJ. Are there any clinical indications for measuring IgG subclasses? Ann Clin Biochem 2002; 39: 374-377.

26 Snowden N, Moran A, Booth J, Haeney MR, Swinson DR. Defective antibody production in patients with rheumatoid arthritis and bronchiectasis. Clin Rheumatol 1999; 18 : 132-135.

27 Stead A, Douglas JG, Broadfoot CJ, Kaminski ER, Herriot R. Humoral immunity and bronchiectasis. Clin Exp Immunol 2002; 130: 325-330.
28 Kang EY, Miller RR, Muller NL. Bronchiectasis: comparison of preoperative thin-section CT and pathologic findings in resected specimens. Radiology 1995; 195: 649-654.

29 Cunningham-Rundles C, Bodian C. Common variable immunodeficiency: clinical and immunological features of 248 patients. Clin Immunol 1999; 92: 34-48.

30 Roifman CM, Lederman HM, Lavi S, Stein LD, Levison H, Gelfand EW. Benefit of intravenous IgG replacement in hypogammaglobulinemic patients with chronic sinopulmonary disease. Am J Med 1985; 79: 171-174. 